\title{
Design for Behavior Change: Transforming Smart Cities public spaces into interactive environments for behavioral changes
}

\author{
Predrag K. Nikolic*, Adrian David Cheok \\ Imagineering Institute, City, University of London \\ Medini Iskandar,79200 Nusajaya, Johor, Malaysia \\ predrag@imagineeringinstitute.org \\ adrian@imagineeringinstitute.org
}

\begin{abstract}
This paper explores potentials of interactive media technology, public spaces and interaction media art and design as potential drivers for behavior changes and social innovations within future Smart City ecosystems. Design for Behavior Change as an approach is already accepted in several key areas such as ecology, safety, health and well-being as well as widely adopted in social design. In the paper are presented two interactive projects InnerBody and Before \& Beyond we used to explore possibilities of Interactive Media Art \& Design in the conceptualization of public spaces, and the way it can affect and provoke user behavioral changes in a sense of increasing user's consciousness related to certain parts of sustainable community development.
\end{abstract}

Keywords Sustainable development, Interaction, Interactive Media Art, Interactive Media Design, Design for Behavior Change, Interface, Smart Cities, Responsive Public Spaces, Multi-Sensory Environments.

\section{Introduction}

Over the past decade design approaches have focused on human engagement capable of achieving social and public well-being. These tendencies are becoming increasingly significant for sustainable development strategies, and widely reflect on a context 
of social innovation [1,2]. The result of such processes and applied design models could come up with new smart services just like any innovation [3], but could also be an idea or social movement which encounter long lasting human behavior change $[4,5]$.

Design has potential to affect human behavior and as such has deep influence on our everyday life. Nevertheless, Design for Behavior Change as a design method is still under development and without clearly defined approaches and frameworks for effective implementation in some of key design areas such as ecological sustainability, safety, health, well-being and social design [6]. In general, achieved changes in human behavior could end up as desirable or undesirable, but design efforts and strategies are always attempting to generate positive changes. Accordingly, Design for Behavior Changes requires from a designer to understand people and predict how people behave in certain situation and to use design to encourage them to 'do', or 'not do' something [6].

This paper has intention to explore opportunities of using Design for Behavior Change as design approach and transform public spaces into interactive multi-sensory responsive environments capable to reflect on peoples' long lasting behavioral changes. Hence, special attention is given to the aesthetical elements, metaphors and meanings characteristic for users' perception of certain everyday forms and objects [7], to maximize user engagement toward meaningful experience which could elicit desirable changes and actions.

We have used Activity Theory as theoretical foundation and research methodologies from user-centered design process [89] where focus is on the thing being designed (e.g., the object, communication, space, interface, service, etc.) to provoke user's behavioral changes. Besides that, the time-space aspect of user experience embedded into natural living environments could be considerably important for future successful transformation of public spaces in Smart Cities into interactive multi-sensory environments where desired behavioral changes are reflecting on people. We believe that interactive media art and design can offer a research environment where people can interact through creative collaboration, aesthetic and experiential level in a way that has immediate impact on the conscious and unconscious perception. That is the reason we decided to use Research through Interactive Media Art [10] and Research through Design as research approach, multi-sensory interactive responsive environments and interactive everyday objects in the spatial design process of transforming Smart Cities public spaces as a 
method to explore potentials for further development of Design for Behavior Change approaches and frameworks.

\section{Background}

Design in its different appearances such as for objects, services, environments etc. has potential to influence human behavior and could create desirable as well as undesirable change [1116]. Design has long history in its intentions to act upon positive changes in human perception and lifestyle. Hence, Designing for Behavioral Change can be perceived through early understanding of behavior [17] where person's behavior is reflection of his or her own personality, or other 'internal' factors and the physical and social environment. Clark [18] divides behavioral change approaches into those which are considering cognition from one side and context from another as the most important elements to shape behavior. Based on that we can use a framework for behavioral change design strategy which is derived from behavioral science but possible to apply in design context [6].

When referring to Design for Behavioral Change models we should go back to 1980's and doctrines of design psychology or behavioral design, terms coined by Don Norman with respect to product design [16]. Respectively followed with the emotion design [19], persuasive technology [20] and design with intent [21] as design models which have been considered more explicit in influencing human behavior.

In this study, interactive installations are used to investigate possibilities of transforming public spaces into smart environments where Design for Behavior Change can be applied and support implications on behavioral change. Interactive media art and recently HCI are intensively involved in investigating design approaches to utilize role of public spaces from merely playful, such as the BBC BigScreen Red Nose game [22] to diversity of aims and purposes [23] such as cultivating social values and sparking political discourse. Use of interactive multisensory responsive surrounding as a tool for experience design and better understanding of user interactions is revealing a plethora of possibilities in a new media design language where components are not only visual and verbal [24] but also experiential as participant can see and hear (and potentially feel) the response of the installation to his or her actions. Interactive projects presented in this paper are trying to provoke behavior 
change and design aesthetic and emotional users' experience, by allowing them to "escape the limitations of existing structures of meaning and expectation within a given practice" as with the Fictional Inquiry technique used by Iversen and Dindler [25], and to experiment with new ways of communication supported with interactive technology. In that sense Iversen and Dindler [25] describe the concept of aesthetic as "a profoundly meaningful transformation that provides a refreshed attitude towards the practices of everyday life, and as a change in our modes of perceiving and acting in the world”. As such we are in positon to use various aesthetical interventions and artistic dynamic forms in Design for Behavior Change approach which aims to change a way we act and react upon ours or others behavior. The use of artistically conceptualized public environments may result in better, more intensive, reflection on user behavior change and eventually to more innovative design approach that cannot be articulated on a purely conscious level [26].

Smart space is a responsive collaborative environment, which requires involvement of interdisciplinary fields such as computing, architecture, industrial design, interaction design, engineering and cognitive psychology for the development. Most researchers are still using laboratory settings to demonstrate potentials of smart technologies but they are missing from their consideration importance of human dimensions such as emotional, perceptive, interpersonal, mindful etc. Consequently, significant effort is needed to develop an interdisciplinary design framework that could express various viewpoints on smart computing technologies, while emphasizing the potential applications of smart spaces to transform our living environments [27].

Interactive installations InnerBody and Before \& Beyond are artistic projects done by Predrag K. Nikolic with interaction design conceptual intention to trigger internal processes such as perceptive, mental, cognitive and emotional and express them through external actions in a form of participants' behavioral changes. By placing them in a public space augmented with sensors, tactile and sensory technologies our aim is to transform living surrounding into multi-sensory aesthetically composed environments, where artistic language and creative concept could contribute to a Design for Behavior Change methods and further development of design approaches within this field. We will describe the interactive installations conceptual, interactive and spatial elements of the created environments for the research experiments. Special focus will be on participants' observations and description of their experience within the installations. Accordingly, we will evaluate collected data and 
validate proposed method as contribution to sustainable design choice within smart cities living ecosystems.

\section{Interactive Projects InnerBody}

We developed InnerBody as an interactive installation where participants are invited to interact with the interface, shaped as model of the human heart, and take a preventive medical exam. The installation was exposed for the first time in 2014, and for that purpose public space of a medieval Belgrade Fort was transformed into improvised ambulance with hanging white sheets, MRI scans and odors we are usually attaching to hospital environments. Before entering the interactive part of the installation visitors were watching video showing MRI examination which the installation author has done on himself for the installation (Fig. 1). Participant were entering the installation space and been informed about the type of the examination they will be exposed and directed to touch the model of human heart and how they can start with medical exam, they did not know it was fake. The transformed public space into interactive multi-sensory environment base on tactile, olfactory, audio and visual experience design has a critical role in provoking desired behavioral changes and support proposed design approach.
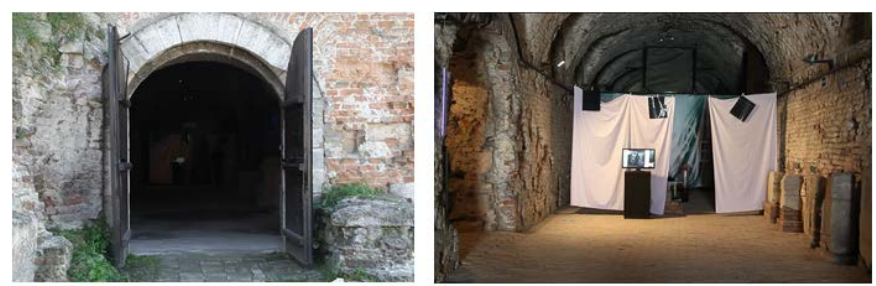

Fig. 1. Entrance of the gun storage and the lobby which lead to the installation entrance

Participant were passing through several experiential phases within the installation experience design path. Firstly, they were exposed to the video showing MRI exam and engaging them with audio-visual sensations which referred to desired context. 

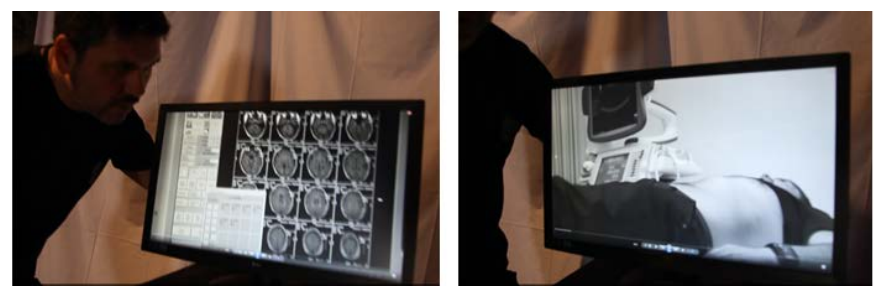

Fig. 2. Video which shows author’s MRI examination

The next step in their experiential path has been entering the main installation space where visitors were exposed to human heart interface, smell suggestive of hospital environment and projected audio-visual system outputs. In terms of design approach and artistic intervention applied on public space transformation, this was the part where aesthetical multi-sensory experience has been mixed with the pragmatic goals of achieving desired behavioral changes (Fig. 3).
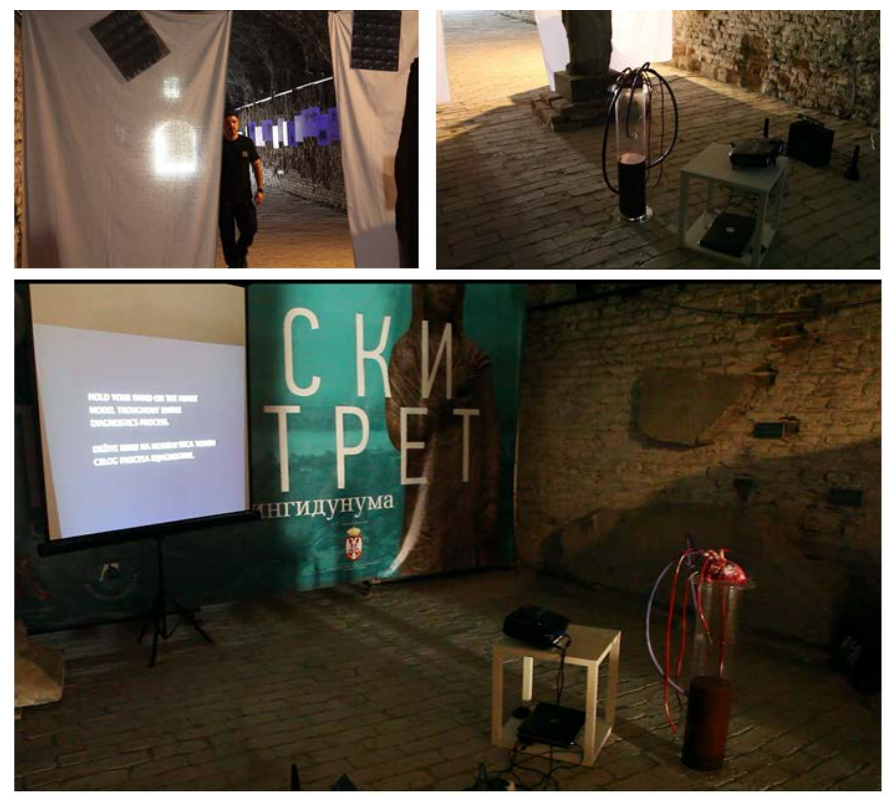

Fig. 3. The Inner Body Heart Interface, the output occurs when user grabs it.

Special attention was given to conceptualization and design of the human heart interface as we considered it as important interaction point in the process of visitors' experience design 
through multi-sensory perception, mainly because of the metaphors and meaning we are addressing to heart, as symbolic representation of vitality, beginning and ending, living and dying, health and sickness [7] and as such can reflect on us emotionally in that context. Visitors were asked to touch the heart to start the simulation of medical exam, which they did not know, and trigger the system outputs (Fig. 4).
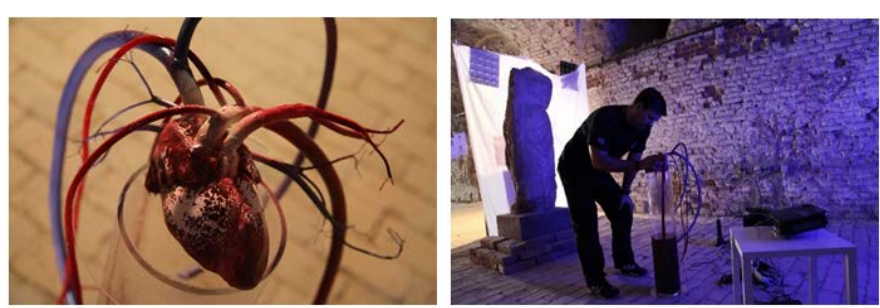

Fig. 4. The Inner Body model of a human heart and cardio-vascular system interface

Audio-visual outputs were controlled sound of heart beats and visual representation of several vital functions in human body. By establishing interactive multi-sensory dialog between users and the system outputs, even they have not been related to their physical state, we had an intention to explore potential of using symbolic, spatial and sensory language to affect their awareness and achieve desired health behavioral changes.

The data in the InnerBody experiment were collected from the following sources:

- Personal observation - the data was collected on the spot, while the users were interacting with the installation, before entering, and after leaving the installation; and

- User interview - this method was conducted after users' interaction with the installation.

Two groups of users participated in the InnerBody interface. The first group consisted of participants who were introduced to the installation narrative prior entering it. They were told about the idea, the purpose, and they knew what to expect. The second group included the participants who did not know anything about the purpose and the functioning of the installation prior entering and, hence, did not know what to expect as an outcome. Total number of 32 participants were personally observed while interacting with the installation -6 of them were told about the purposed of the installation, while 26 were not. Our basic as- 
sumption was that the first group of participants, who were familiar with the installation narrative, would be more indifferent to the outcome of the installation procedure then participants of the second group, who would become much more frightened and concerned about their health condition.

As mentioned before, the InnerBody interface was the stylized model of a human heart and cardio-vascular system. The forms, objects and its representations were something that the participants would easily recognize once they enter the installation. Nevertheless, the model of the human heart, the sound of a heartbeat, the scent of medicines, and hospital-like white sheets were the elements with the purpose of triggering human sense of concern about health condition and the fear of dying. Participants were instructed to grab the model of the heart, which was slightly bigger than the normal human heart, to start "self-medical exam" and trigger the system. The first stage was observing participants while reading the instructions prior entering the installation. The only sound that could be heard while reading was the sound of MRI machine. In most of the cases, the expression on the faces of the participant would quickly turn from smiling to serious. During the upcoming interviews the participants stated that the sound of the MRI machine in combination with the instructions about the possible health condition that could be "found out" during the session, provoked a sense of urgency, alert, and even sudden fear inside of them. One of the participants, a 41-year-old male, said that suddenly he just felt he had to be serious about the "procedure". The second stage of the observation was watching participants grabbing the heart model to start the "examination”. Many the participants grabbed the heart model very gently to start the process. Later, during the interviews, we learned there were two reasons for such behaviour: the first was the sense of discomfort provoked by reading the instructions and hearing MRI, and the second was the sense of uncertainty about the upcoming "examination". The third stage of our observation was monitoring the effects of different stimuli of the installation on the four senses of the participants: sight, hearing, smell and touch. Per environmental psychology, different stimuli from the outside world influence our senses [28], triggering the response of human organism (stimuli-organism-response, SOR model). The responses range from: dissatisfaction to satisfaction, from tension to relaxation, and from inferiority to superiority over situation. It helps us understand the reasons behind human behaviour changes. Most of the behaviour change is driven by mental state which is usually affected by external stimuli. Touching heart model was fun for most of the participants, but only for a while. In case of three participants, a 42- 
year-old woman, a 18-year-old girl, and a 26-year-old man, it turned out to be an unpleasant experience. The paint of the heart model stained their hands. The red stains on their hands they instantly misinterpret as blood. During our experiment, in most of the cases auditory stimuli such as the sound of MRI machine, caused tension in sense of concern for participant's health state. On the other hand, the message at the end of the "examination", informing that the whole procedure was not a real examination, brought back the sense of relaxation and superiority over the situation to the participants. On the other hand, visual stimuli, such as watching monitor displaying fake heartbeats, in most of the cases made participants get serious expression on their faces. The fourth stage was observing participants in the final stage of their "examination" when getting informed about the "results". As previously stated, at the end of the session, the participants were informed about the purpose of the installation. It was interesting to observe changes of their facial expressions as well as the changes in their overall behaviour. The tension was replaced by relaxation, the concern was replaced by happiness after they had got informed the whole "examination" was not real. Still, the final stage of the installation conveyed the sense of warning which effects were supposed to be interrogated through interviews with the participants.

User interviews were structured and done in the form of an informal, open conversation with participants. The goal of the interviews was to reveal the change in participants' behaviour based on their experience. The questions were split in two phases:

Phase 1 included questioning conducted minutes after leaving the installation. The questions were the following:

i. Describe your experience during interaction with the installation.

ii. Describe your feelings related to different stimuli: sound, pictures, smell, and touch.

iii. Can you say there is the difference in your feelings before entering the installation and after leaving it?

Since the purpose of the installation was to create the sense of moderate fear and concern about the participant's health state, it was important to have a follow-up on the installation experience. Phase 2 was the follow-up phase conducted three month after the installation experience. The questions posed were the following:

iv. Since the installation, have you taken any kind of physical examination?

v. If you have, can you say that the urge for physical 
examination was provoked by your installation experience?

The first phase of user interviews was conducted on 12 participants: 5 from the first group who had been introduced with the installation narrative, and 7 from the second group, who had not been introduced with the installation. Although we had assumed that the participants from the first group would be more indifferent to the outcome of the experienced "examination" than participants from the second group, user interview phase 1 showed that there were participants from the first group who reacted dramatically to the stimuli they were exposed to. One of the users, a 42-year-old woman who had been introduced to the installation narrative stated out that when she placed her hands on the heart model her experience became so realistic that she was convinced that she could hear her heart started beating faster, despite the fact she had been told that the sound of the heartbeat would come from the tape. Moreover, 50-year-old woman stated that, although she had been told the installation story, during the "examination" she was trying to recall when was had last appointment with her physician. We decided to follow-up the first group despite our first assumption that it would not be necessary. The second phase of the user interview was conducted on 7 participants: 3 from the first group, and 4 from the second group. Two participants from the first group, who had been familiar to the installation narrative, answered that had developed serious concern about their health condition ever since the installation experience, while one of them even took a medical examination. From the second group, 3 participants made appointments with their physicians.

We concluded that our installation participants were frightened no matter they knew the whole "examination" was not real and that it was a part of a directed, synchronized performance. The participants understood the metaphors used in the installation, since the communication between them and the system was clear, easily understandable, and interactive. However, the interactive environment and suggestive objects used to design user experience created substantial amount of fear and managed to change the behaviour of the participants who had been introduced with the installation narrative in the first place. We used deeply inherited fears in our consciousness we react on subconsciously, to provoke desirable effects. We concluded that despite the fact our participants had been aware that it was fake examination, they started being afraid of their deepest fears. Based on that, we found interactive media art and multimodal storytelling as potential environments for design of 
health behaviour change.

\section{Interactive Projects Before \& Beyond}

In the interactive project, Before \& Beyond we tried to transform public space into playful environments where visitors will be engaging around physical interactions between each other and stimulate their internal processes such as motivate them to collaborate, bodily interact and communicate, having thoughts on their existence and natural surround and relate that to need of nearby social engagement and relationships development. The installation was exposed for the first time at the Maison Shanghai 2016 event as part of Final Fantasy exhibition. The space was responsive to visitors' body movements, direction of walking and distance between participants. By entering the installation space visitor was attached to a one String of Energy with characteristic color and sound as an abstract representation of their existence in a virtual world projected as system output on a display placed in-front of them. To accurately track their location within transformed public space we augmented it with sensory based technologies, Kinect movement detection placed on the wall and Beacons integrated in the medallion around the neck of the participants (Fig. 5).

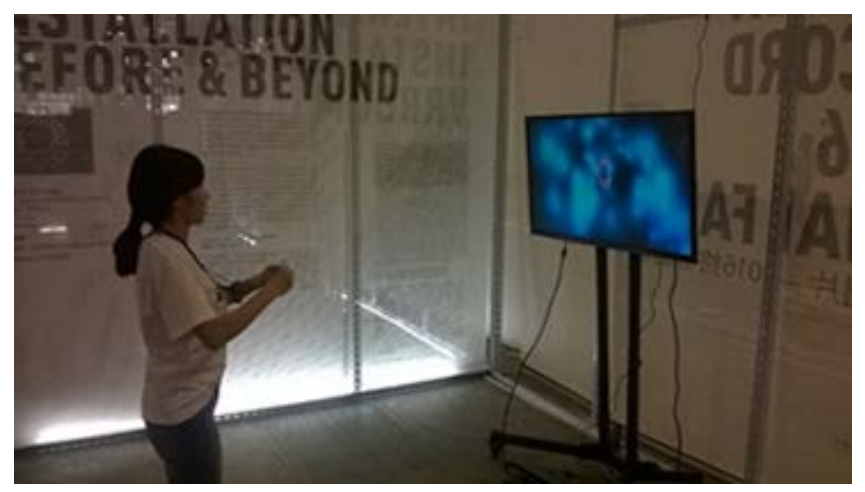

Fig. 5. After entering the installation space, every participant gets his personal String of Energy projected on the screen

Personal Strings, (animated two-dimensional closed line in a shape of circle, enriched with a specific tone and color) which are projected on a screen are following movements and directions of the visitor and reacts on distances between them. When participants are close enough to each other their Strings are 
joining in one and vice-versa when they separate the joint String splits back to personal strings (Fig. 5). Aesthetics experience is accomplished with artist elements such as shapes of the strings, background sound, sound of strings etc. which are referring to the concept of the installation rooted in String Theory and Socio-emotional development connected emotional management and the ability to establish positive and rewarding relationships with others [29].
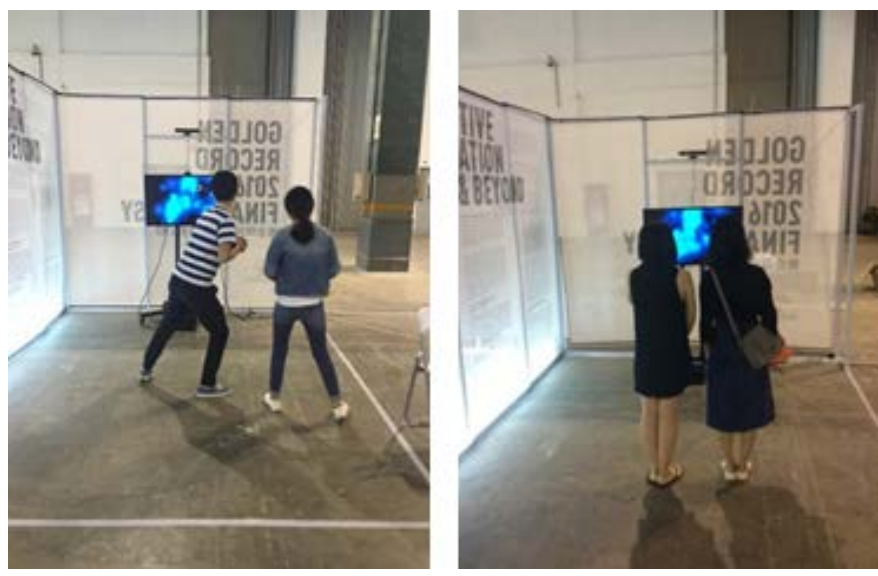

Fig. 6. Depending on distance and established relationships between visitors visual and audio appearance of the Strings changes

Interaction concept of the Before \& Beyond installation is to intrigue visitors to explore their own virtual existence and correlate it with others within a transformed public space. During that process, they are acquiring new personal properties such as color, shape and sound attached to their String. After become an aware of it, to trigger social and cultural dimensions where they are becoming interested in collaboration with others and to development new relationships within given context. In our case, physical as well as virtual space are becoming a place for body and social interactions and for strengthening our interpersonal relations as essential requirement for running social initiatives within communities with common goals and needs.

In case of the interactive installation Before \& Beyond we based our concept per idea that depending of content, context and public space structure we are in position to affect the social situation. For example, the degree of intimacy and how people will move and behave in the space influences aesthetic and interaction concept that will work well [30]. In case of the instal- 
lation Before \& Beyond users are moving around in the responsive space in front of the display, the interaction space between the users and display is an agent which connects visitors' efforts and actions in physical space with virtual audio-visual outputs. By moving around and interacting between each other participants are shaping social space same way they are doing with their own everyday living surround. Public space configuration and context affect the social space, individual and interpersonal interactions as the performer is not isolated but in a group.

The data in the Beyond \& Before research experiment were collected from:

- Personal observation.

- User interview.

The goal of the interviews was to reveal the change in participants' behaviour based on their experience. The questions were the following:

i. Describe your experience during interaction with the installation.

ii. Describe your relationship with other participants: before entering the installation, during a session and after leaving the installation space.

iii. Describe how spatial circumstances and environment affected your experience and behaviour.

Through observations and informal interviews with the participants we find out that period they were alone in the installation space was not interesting and for some of them pointless. Per their answers they tried to understand relation between their movements and the sting behavior, limitations and the system responsiveness. After leaving the installation they were not interested to enter it again. The mayor behavioral transformation happened when in cases they were accompanied with other visitors. The elements of collective efforts and needs to physically interact between each other changed their experience to more engaging and socio-tactile. Most of them describe it as: We've been involved into playful game with total strangers. At the beginning we tried to explore relation between our spatial positions and how they reflect on Personal Strings movements and system's audio-visual outputs. From the moment, they realized they could join the strings by lowering down the distance between each other and getting in physical contact, started to stick together, bodily interact and hug each other. Majority of the participants explained that before entering the installation they did not have any intention to interact with other participants, 
then after figuring out dependence between body position and Personal String they wanted to know what will happen if they touch with other strings. They started to shorten a distance between them and others and spontaneously got voluntarily involved in unexpected types of body interactions (hugs, holding hands, touching body parts, etc.). According to participants' testimony, after been so close to each other, they changed their socio-emotional attitude related to people involved in the collective interaction, started to talk with them after leaving the installation and wanted to enter the installation again.

\section{Conclusion}

In the interactive project InnerBody we concluded that despite the fact our participants had been aware that it was fake examination, they started being concerned for their health condition which motivate some of them to take real preventive medical exam. Based on that, we found interactive media art with its aesthetical preferences and placed in public spaces could be used as potential design tool we can contribute to new approaches and frameworks within Design for Health Behaviour Change field.

With same preferences, we can address findings from interactive project Before \& Beyond as in this case we also provoked instant participants' behavioral changes and generated new types of socio-bodily interactions which affected user experience. Social situation, within transformed public space, joint participant into group where all individual efforts were dedicated to common goals. As result we manage to change their social behavior which resulted with new interpersonal and emotional relationships.

Furthermore, we are planning to expose InnerBody and Before \& Beyond interactive installation under different sociocultural and spatial circumstances and conducted a systematic iterative data analysis after that, focusing on spatial and contextual aspects within and compare them with the observed social situation and behaviors [30]. In our future research directions, we want to better understand potential of interactive media art and design, and propose it as new Design for Behavioral Change approaches as well as to develop a design model for using public places in Smart Cities to provoke new types of interactions for human behavior change and social innovation. 


\section{References}

1. Manzini, E. : Viewpoint: New Design Knowledge, Design Studies, 30(1):4-12 (2009)

2. Emilson, A., Seravalli, A. \& Hillgren, P.: Dealing with dilemmas: Participatory

approaches in design for social innovation. Swedish Design Research Journal, 1(11):23-29 (2011)

3. Murray, R., Caulier-Grice, J., Mulgan, G.: The open book of social innovation. London, The Young Foundation \& NESTA (2010)

4. Bjögvinsson, E., Ehn, P. \& Hillgren, P.: Design things and design thinking:

Contemporary participatory design challenges. Design Issues, 28(3):101-116 (2012)

5. Design Council: What's Dott? [online]. http://www.dottcornwall.com/aboutdott/ whats-dott (2010), [accessed 27 October 2011]

6. Kristina Niedderer, James MacKrill, Stephen Clune, Martyn Evans, Dan Lockton,

Geke Ludden, Andrew Morris, Robin Gutteridge, Edward Gardiner, Rebecca Cain,

Paul Hekkert: Joining Forces: Investigating the influence of design for

behaviour change on sustainable innovation (2014).

7. Nikolic, P., Multimodal Interactions: Embedding new meanings to known forms and objects, Lecture Notes of the Institute for Computer Sciences, Social Informatics and Telecommunications Engineering 2016 B. Mandler et al. (Eds.): Internet of Things $360^{\circ}$ 2015, Part II, LNICST 170. DOI: 10.1007/978-3-319-47075-7. Springer International Publishing. (2015).

8. Mike Kuniavsky, Observing the User Experience: A Practitioner's Guide to User Research (Morgan Kaufmann Series in Interactive Technologies) (The Morgan Kaufmann Series in Interactive Technologies), Morgan Kaufmann Publishers Inc., San Francisco, CA, 2003

9. Thomas Tullis, William Albert, Measuring the User Experience: Collecting, Analyzing, and Presenting Usability Metrics, Morgan Kaufmann Publishers Inc., San Francisco, CA, 2008

10. Sommerer, C, Mignonneau, L. Interactive Art Research, Springer Vienna Architecture, 2009.

11. Brown, T., Wyatt, J.: Design Thinking for Social Innovation. Stanford Social Innovation Review, (Winter) (2010)

12. Consolvo, S., McDonald, D.W., Landay, J.A.: Theory-Driven Design Strategies for

Technologies that Support Behaviour Change in Everyday Life. In: Proceedings of the CHI2009: Creative Thought and Self-improvement. Boston, MA, ACM Press (2009)

13. Fry, T.: Design Futuring: sustainability, ethics, and new practice. Oxford: Berg, (2008) 
14. Lockton, D.: POSIWID and determinism in design for behaviour change. Working Paper

Series, Brunel University, April (2012), URL:http://bura.brunel.ac.uk/handle/2438/6394

15. Niedderer, K.: Mindful Design as a Driver for Social Behaviour Change.

In Proceedings of the IASDR Conference 2013. Tokyo, Japan: IASDR (2013)

16. Norman, D.: The Design of Everyday Things. New York, USA, Basic Books (2002)

17. Moggridge, B.: Innovation through design. International Design Culture Conference,

Korean Design Research Institute, Seoul National University: IDEO (2008)

Behavior and Technology Development, Springer, Berlin, pp. 222 (2006)

18. Lewin, K.: A dynamic theory of personality. New York, McGraw Hill (1935)

19. Clark, G.L.: Human nature, the environment, and behavior. SPACES online, 7:1 (2009)

20. Desmet, P.M.A., Overbeeke, C.J., Tax, S.J.E.T.: Designing products with added

emotional value. The Design Journal, Vol.4, No.1, pp 32-47 (2001)

21. Fogg, B.J.: Persuasive Technology: Using Computers to Change What We Think and

Do. San Francisco, USA, Morgan Kaufman (2003)

22. Lockton, D., Harrison, D.J., Stanton, N.A.: The design with intent method: a design tool

for influencing user behaviour. Applied Ergonomics, Vol.41, No.3, pp 382-392 (2010)

23. Fatah gen. Schieck,A., Briones, C., and Mottram, C., “The Urban Screen as a Socialising Platform: Exploring the Role of Place within the Urban Space,” MEDIACITY: Situations, Practices and Encounters, Frank \& Timme, 2008, pp. 285-305.

24. O’Hara, K., Glancy, M., and Robertshaw, S., "Understanding Collective Play in an Urban Screen Game,” Proc. Computer Supported Coop.

25. Sanders, E.B.-N.: Generative Tools for CoDesigning. In: Collaborative Design, Scrivener, Ball and Woodcock (Eds.). London, Springer-Verlag (2000)

26. Iversen, O.S., Dindler, C.: Pursuing Aesthetic Inquiry in Participatory Design. PDC conference (2008)

27. Nelson, H., Stolterman, E.: The Design Way - Intentional Change in an Unpredictable World. Foundations and Fundamentals of Design Competence. New Jersey, Educational Technology Publications, (2003)

28. Hoffman, K.D., Bateson, J. E.: Services Marketing, Cengage Learning (2011) 
29. Cohen, J., and others. 2005. Helping Young Children Succeed: Strategies to Promote Early Childhood Social and Emotional Development Washington, DC: National Conference of State Legislatures and Zero to Three.

30. Fischer, P. T., Zollner, C., Hoffmann, T., Piatza, S., \& Hornecker, E. (2013). Beyond Information and Utility: Transforming Public Spaces with Media Facades. IEEE Computer Graphics and Applications, 33(2), 38-46. DOI: 10.1109/MCG.2012.126 